\title{
Online Democratic Deliberation in a Time of Information Abundance
}

\author{
Craig Bellamy
}

The intensified use of the Internet by civil society groups and governments for political purposes has left many questions unexplained-especially in terms of the Internet's effects upon deliberative democratic processes. The Internet was first imagined as a means to revitalize deliberative processes. However, poor design and lack of usability research meant that many ambitions went largely unrealized. With a new wave of Internet technologies, 'deliberative design' has become even more important to stem what many claim is a trend towards political fragmentation and disaggregation. In a time of 'information abundance' mounting political communication online may also undermine collectivist, deliberative democratic processes, distinct from the ambition to renew these processes. There is therefore a pressing need to design Internet technologies that serve deliberative democracy, rather than unwittingly undermine it.

\section{Political Communication and Information Scarcity}

The Internet arrived on the global stage during a tumultuous juncture in world history. The Soviet Empire collapsed, ending fifty years of ideological battle between the centralized command economies of the Communist East and the free-market economies of the capitalist West. A world that was sharply divided between the Socialist ideologies of centralized planning_coupled with tight information controls_ and the capitalist ideologies of individual agency and individual expression was superceded by a world of increasingly unfettered 'flows'. Primarily driven by the United States, its allies, and the post-World War II Bretton Woods Institutions such as GATT (General Agreement on Tariff and Trade), freedom of expression, trade, and of the market came to dominate international relations. The Internet entered the global arena during this period of great change; it was both defined by this change and defined this change (and it may have developed very differently if it was conceived during another period of history). It is not unusual, therefore, that during the tentative entry into the post Cold War period, many early researchers understood the Internet's political potential as one firmly grounded in 'information scarcity' and in censorial anxieties that derive from the ideological divisions of the 'short Twentieth Century' (Hobsbawn 1994).

Early commentators and cyberenthusiasts were quick to promulgate the democratic potential of the Internet, and claimed that the new technologies, free of censorial 'gate keeping', would enliven political debate, facilitate direct democracy, and empower citizen participation in grassroots, bottom-up political exchange among citizens and between citizen and state (Negroponte 1995; Rheingold 1995; Toffler and Toffler 1995; Dyson 1998). However, the increased ability for all groups and individuals to advance their concerns online also advances risks to broader, collective and deliberative decision making.

\section{Political Communication and Information Abundance}

The history of political communication is intimately connected to the history of broader technological 
innovation and political actors have always adapted the communication mechanisms at their disposal, whether they be radio, film, television, or newspapers (Bimber 2003). The Internet is no exception and there are many case studies that examine the Internet's political efficacy within a plethora of campaigns (Bergman 2003). However, the bulk of these studies tend to promote a view of technological determinism that over-emphasizes the role of self-publishing for broader, informed, and collective decision-making (Bimber 2003; Oates, Owen and Gibson 2006). Some have argued that the individualized and opinion-centered nature of the Internet and new technologies in general may also lead to disaggregation, information overload, less deliberation and greater levels of apathy among citizens (Shenk 1997; Bimber 1998; Oates and Gibson 2006).

It is the idea of 'information overload', or what Bruce Bimber refers to as 'information abundance', that is rarely addressed in discussions of civil society and online political communication (Bimber 2003). The Internet and other new media have long reached a critical mass so tapered discussions on the empowering nature of self-publishing and the obviation of 'gate keeping' and political censorship seem unrealistic in societies now defined by too much information. As Bimber observes:

...when citizens are given greater capacity to select among multiple media sources, they are most likely to make selections to narrower and more compatible viewpoints. That is, citizens do not use a richer and more diverse media environment to better inform themselves about conflicting ideas and positions, but instead select a narrower and more parochial set of sources (Bimber 2003:208, quoting Mutz and Martin, 2001).

Succinctly, Bimber (2003) and Mutz and Martin (2001) assert that when faced with 'information abundance' citizens do not necessarily seek information to deliberate, but seek information to bolster their prior political beliefs. This can result in the formation of 'information islands' of insular pockets of political discourse far removed from broader, deliberative discussions of pluralistic society and its democratic structuring (Carson 2006). These political information 'islands' (or insulated networks) may sustain, racial Diasporas, gender issues, or class factions. They could likewise facilitate powerful epistemic advocacy, concentrations of wealth, religious politics, or other formations of social, political, or 'human capital' (Bourdieu 1998). As Heinz Brandenburg (2006) explains:

By encapsulating into narrowly defined interest groups and customising the information flow, the user potentially disconnects from the larger society, moving towards either individualisation or intensified small-group association (Brandenburg:218).

Nevertheless, Shenk (1997), Bimber (1998), and Brandenburg's (2006) considerations of the looming threats of 'information abundance', and its complex relationship to deliberative democracy, have been somewhat speculative. This is perhaps because the notions of 'information abundance' and democratic deliberation were largely exterior to the core aim of their research and because at the time of some of these studies 'information abundance', coupled with its recent technical redress, was not as significant as it is now. The Internet currently has over one hundred million sites and is exploited by all political parties as well as thousands of civil society groups of all political persuasions. It is accessed regularly by the majority of the population in all Western developed nations and has become a central component of our political information system . Furthermore, the Internet was never a finished project anyhow and the recent technical developments that flock around the term 'Web2.0', considerably alter how we understand and make use of the Internet especially in terms of how individuals filter and order the plethora of political information online (O’Reilly 2005).

\section{Information Filtering: A Response to Information Abundance}

Web 2.0 - a popular term that refers to an emergent set of online practices and technologies-is, in part, a response to 'information abundance'. It affords such knowledge organization possibilities as user-centred ordering and filtering of cogenerated information through features such as social classification (called 'tagging' or 'folksonomies') and RSS Feeds (Really Simple Syndication). Web 2.0 also gives rise to what many claim is rapidly becoming a 'real time' web through systems that allow the visualization of the 'subjects' that are being 'discussed' on a good portion of the global Internet in real time (albeit in a somewhat asynchronous 'real time', i.e., like blogging and pod casting). This is highly useful for examining how political communication is ordered and discussed within broader society. Folksonomy - the opposite of taxonomy-is a cornerstone of Web 2.0 and refers to a system of 'bottom-up' user-generated categorization (or tagging) of online digital objects such as articles, blog entries, video, photos, and sound files. 
User-generated tags can be aggregated into 'tag clouds', thus making it possible to visualize, albeit in a nascent and rudimentary way, the data aggregating across or within any given network and repository. Folksonomies, such as those provided through the popular new filtering systems Technorati.com and Del.icio.us, allow users to visualize what is being discussed by users on their systems in real time. Cursory periodical glances at Technorati reveal that at least $20 \%$ of the 'top tags' are at times allied to political discussions (albeit mostly U.S.-centric). See Figure 1.

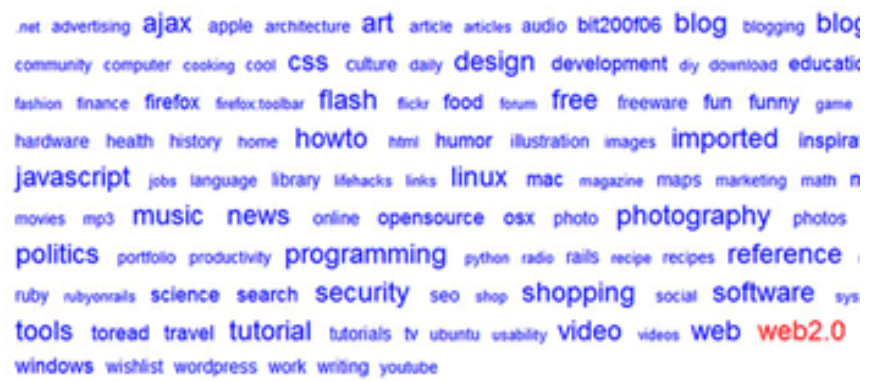

Figure 1. A user-generated folksonomy or 'tag cloud' from the social bookmaking site del.icio.us

There is a growing awareness of the significance of 'folksonomy' and usercentred classification, especially within the information sciences. (Yakel 2006) The idea of 'everyday' classification of the ways in which people interact, produce, and distribute (political) information has immense research potential.

Folksonomies or 'social classification' (Hammond et al. 2005) are by no means the only technological response to the dilemmas of ordering information in systems increasingly clogged by information. Wikis such as Socialtext. com, online news sources like Digg.com, Youtube.com, and popular new 'television stations' such as Al Gore's Current.tv, all place user-centred information creation, ordering and retrieval at the center of their respective models. Thus users have the ability to rate, filter and hierarchize information either collectively (as in the case of Digg.com), or individually through membership based networks, as in the case of Youtube.com.

Thus we are entering a period of information abundance with a number of inventive technical responses to that abundance. In a recent forum at the Oxford Internet Institute at the university of Oxford, the Inventor of the World Wide Web, Tim Berners-Lee, claimed that the global email system was on the verge of collapse simply because there are too many emails (Berners-Lee 2006). Systems such as Socialtext.com, a Wiki style system for large enterprises such as universities, have risen in popularity to deal with 'information abundance' and the problem of email overload and ineffectiveness. Hence, there are some parallel lines of technical development and thought here that could benefit from a much more rigorous encounter. First, a number of Internet and political communication theorists recognise the dangers of 'information abundance', especially upon discourses of deliberative democracy (Bimber 2003; Brandenburg 2006; Carson 2006). Second, a series of technical innovations, commonly referred to as Web2.0, partly address the broader problems of information abundance. Thus the question remains: how can new ways of filtering, creating and ordering knowledge be used to better design online deliberation?

\section{What is Effective Deliberation?}

To address this question, there is need to first delineate what is 'deliberation'? Deliberation can take a number of forms depending on the political and social context of the stakeholders and their relationships to the subjects being discussed. Deliberation can involve individuals and groups from the full political and social spectrum, so there is a need to be flexible. Some technologies may not be suitable to particular social and political contexts as low 
'technical capital' within a certain group may impede online deliberation or some subjects may not be well-rendered online. Deliberation is a form of public engagement; it is the desire to inform and involve citizens in decision making processes within the issues that concern them (Coleman and Goetz 2001). This could be a proposal to extend a freeway though a district or a proposal to build a new school or to open a new fast-food outlet. It could likewise entail a debate on global warming or the considerations of an article's appropriateness for publication in a scientific journal. Methods of engaging individuals are deliberative if they encourage individuals to critique, discuss, synthesize and judge competing positions and options usually within a rule-based and goal oriented forum. Deliberation encourages individuals to make informed decisions rather than simply assert opinions. Drawing on definitions distilled from the work of Coleman and Goetze (2001), Fishkin (1991), and Kavanaugh et al. (2005) the following working definition of deliberation is a useful starting point:

- Access to balanced information-Deliberative processes are primarily concerned with discovering what citizens think about issues once they have become informed about the various options. The information given to citizens must be comprehensive, balanced and accessible.

- An open agenda-Deliberative questions are likely to set out the broad parameters of the anticipated discussion and the agenda must be open to revision and expansion.

- Time to consider issues expansively-Deliberative exercises must be temporally expansive, allowing citizens adequate time to think through an issue and then work out their position on it.

- Freedom from manipulation or coercion-All political exercises are at risk from manipulation, whether in subtle terms such as rigging the questions or in pressuring the participants to arrive at certain conclusions

- A rule-based framework for discussion-Democratic deliberation is not a Libertarian free-for-all. People feel safer and discuss more freely when they are aware of the transparent rules of the debate

- Participation by an inclusive sample of citizens-High quality deliberation can be highly exclusive, but not if it purports to be democratic. Efforts must be made to recruit participants who are representative of those affected by or concerned about the issue being considered.

- Scope for free interaction between participants-Deliberative exercises require citizen to citizen interaction as well as citizen to government. Participant must have access to other participants to discuss and debates the main points.

- Recognition of difference between participants, but rejection of status based prejudice-Deliberation means that expert opinion does not override the deliberative processes of the citizens but become a component of 'balanced information'.

- Goals-What are the specific goals of the deliberation and are they meaningful and consequential and are they being met?

Much online political communication is poorly designed with few of these or any other deliberative ideas embedded within its technical processes. It may lack balanced information and the ability for individuals to seek alternative opinions either through linking to outside sources or through discussions with other participants. Often political communication online is little more than a series of opinions with few clues as to how those opinions were derived upon and where they are leading. Many government organisations simply imagine the Internet as an efficient 'delivery boy' of written policies, rather than as a means to engage citizens in a meaningful way utilising the deliberative potential of the read-write web. In the early days of the Internet, publishing political information online was seen as an end in itself; it was seen as a way to obviate the censorial ambitions of the State and as a cheap and efficient means to distribute political ideas outside of mainstream commercial media or other 'gate keeping' mechanisms. But now, there is just so much political information online that it forms a defining electronic 'noise' that is difficult to navigate and comprehend in a meaningful and purposeful manner. Democratic processes do not just happen; they are cooperatively designed and there is a growing need to design the Internet to support democratic deliberation rather than incessantly support the selfish Libertarian and noisy self-interest of laissez-faire capitalism.

\section{| Designing Effective Deliberation}

As noted by Heinz Brandenburg (2006), there is an emergent 'Atlantic divide' between the United States and Europe in terms of the application of the Internet for political communication:

The position of cyber-enthusiastic citizens as well as academics and cyber-literate politicians in the United States appears to be that the Internet can self-manage in the absence of any form of government intervention, censorship and legislation. In contrast, the dominant position amongst scholars and policy makers in mainland Europe as well as in the United Kingdom is that we need constitutional engineering beyond giving mere access to people, namely the proactive creation of constitutive 
elements of a virtual public sphere, funded and partially initiated by public institutions (Brandenburg: 215).

In my own home country of Australia, our most well-known initiatives tend to be somewhere between these United States and the European trends; this is perhaps not that unusual given the historic role the two powers have had within Australia. Our initiatives tend to range from attempts to design elements of a 'constitutive public sphere' through sites such as Nationalforum.com.au and Newmatilda.com, to the at times Libertarian immoderation of the global Indymedia.com network, built on software originally designed in Sydney. Australian online political communication is somewhere between the BBC's Action Network (bbc.co.uk/dna/actionnetwork) and the highly successful United States based Moveon.org.

A recent example that utilizes 'ideal' deliberative design coupled with emergent Web2.0 tools is the ActNow. com.au initiative. ActNow is a project for young people and seeks to provide a forum where they can discuss political issues online. It attempts to provide balanced information and forums to discuss, for instance, questions surrounding poverty, multiculturalism, and sustainable energy. Of particular note is that the site utilises 'folksonomies' to highlight and hierarchize the 'hot issues' being discussed by users. The users can comment on stories and then rate them according to a poll-driven 'care factor' that determines which issues appear on the front of the site and in which order. The site does not claim a monumental political efficacy, like some of the original online political initiatives, but simply seeks to provide a space where young people can discuss issues and become more informed on these issues so as to increase their confidence to act within the community. See: Figure 2.

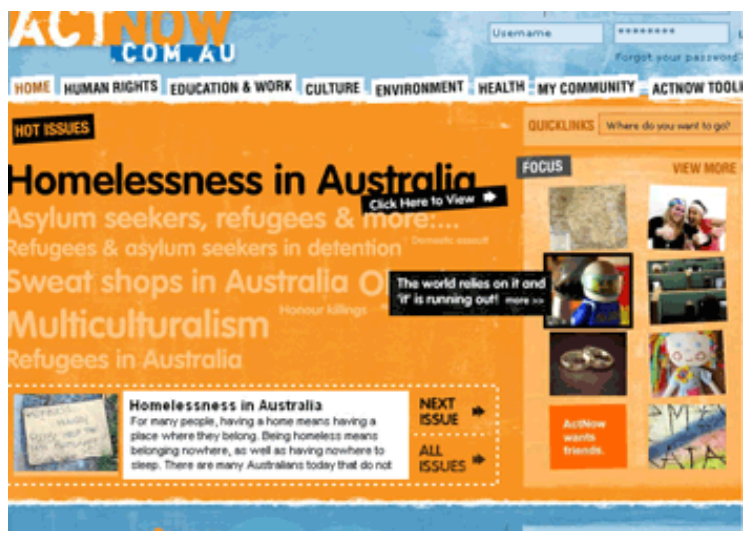

Figure 2. Presents an example of political communication within a civil society group in Australia. www.actnow.com.au is a novel example of how Web2.0 is being utilised by young people within Civil Society within Australia. It utilised a system called a 'care factor' so that the technically savvy participants can deliberate upon, rate and hierarchize broader political concerns.

It is the ability to integrate information in new ways and the ability to engage users as codevelopers that I find extremely exciting about this project (Yankel 2006). It is a form of design that seeks to advance collective knowledge about social issues through a rule-based, goal oriented, deliberative system. However, this is just one isolated example of online deliberation and for deliberation to be truly effective there is need to elicit involvement from more groups. 'Interoperability' or the ability for groups and individuals to engage with one another is one of the central components of 'ideal deliberation' and one of the central principles of Web2.0 (Coleman and Goetze 2001). New tools can be harnessed to compare 'knowledge maps' between groups and broker and invite collaboration that can perhaps address some of the emerging issues of political fragmentation and diminished deliberation online. Systems need to be designed that are open and 'interoperable' and that enable the efficient sharing of knowledge between diverse deliberating groups. The ability for users to form useful relationships around common political interests will better facilitate the processes of deliberation within meaningful, inclusive, and consequential political processes. The potential benefits of these technologies are immense and much that is positive can flow from the application of these tools to worthy political processes.

To conclude, the information revolution brought about by new technologies may also be fostering information 
abundance, disaggregation, political fragmentation, and less considered understanding of our political processes and the choices that they provide. As argued, deliberative 'ideas' are seldom well-designed into the structure of online political initiatives, perhaps because there is not enough understanding of what deliberation is online and how it can be better designed. Our economy, culture, and polity are undergoing profound changes due to the impact of new technologies and our relationship to this information and the political messages that it contains is also changing due to its ever increasing abundance and delivery mechanisms. We need to provide new understandings of the relationship between citizens and the political communication processes of the Internet so these processes can be designed better to support stronger deliberative and thus democratic ideals.

\section{References}

Bimber, Bruce A. 2003. Information and American Democracy: Technology in the Evolution of Political Power. Cambridge:Cambridge University Press.

Bourdieu, Pierre. 1984. Distinction: A Social Critique of the Judgment of Taste. Translated by Richard Nice. Cambridge, Mass:Harvard University Press.

Brandenburg, H. 2006. "Pathologies of the Virtual Public Sphere." Pp. 207-222 in The Internet and Politics: Citizens, Voters, and Activists, edited by S. Oates, D. Owen, and K. Gibson. New York:Routledge.

Burgmann, Verity. 2003. Power, Profit and Protest: Australian Social Movements and Globalization. Crows Nest, NSW:Allen and Unwin.

Carson, I. 2006. "Avoiding Ghettos of Like-Minded People: Random Selection and Organizational Collaboration." Pp. 418-423 in Creating a Culture of Collaboration, edited by S. Schuman and Jossey Bass/Wiley.

Coleman, S. and J. Gotze. 2001. "Bowling Together: Online Public Engagement in Policy Deliberation., Hansard Society Retrieved November 21, 2006 (http://www.bowlingtogether.net/bowlingtogether.pdf).

Dryser, J.S. 2000. Deliberative Democracy and Beyond. Oxford:Oxford University Press.

Elster, J., ed. 1992. "Introduction.” Deliberative Democracy, Cambridge:Cambridge University Press.

Ferdinand, Peter, ed. 2005. The Internet, Democracy and Democratisation. London:Routledge.

Fishkin, James. 1991. Democracy and Deliberation: New Directions for Democratic Reform. New Haven:Yale University Press.

Habermas, Jürgen. 1989. The Structural Transformation of the Public Sphere: An Inquiry into a Category of Bourgeois Society, Translated by Thomas Burger with the assistance of Frederick Lawrence. Cambridge, Mass:MIT Press.
Hammond, T., B. Lund. and J. Scott. 2006. "Social Bookmarking Tools” in, D-LIB Magazine, Vol.11 No.4. Retrieved October 12, 2006 (http://www.dlib.org/dlib/ april05/hammond/04hammond.html).

Kavanaugh, A et.al. 2005. "Detecting and Facilitating Deliberation at a Local Level/" conference paper given at Online Deliberation 2005. Retrieved December 5, 2006 (http://www.onlinedeliberation.net/conf2005/viewabstract. php?id=38).

Oates, S, D. Owen, and RK Gibson. 2006. The Internet and Politics: Citizens, Voters, and Activists. New York:Routledge.

O’Reilly, Tim. 2005. "What Is Web 2.0: Design Patterns and Business Models for the Next Generation of Software?" O’Reilly Media. Retrieved October 6, 2006 (http://www. oreillynet.com/pub/a/oreilly/tim/news/2005/09/30/whatis-web-20.html)

Rheingold, H. 1994. The Virtual Community. Secker and Warburg: London. Retrieved October 4, 2006 (http://www. well.com/user/hlr/vbook).

Shenk, D, Data Smog. 1997. Abacus:San Francisco.

Toffler, A. and H. Toffler. 1995. Creating a New Civilisation: The Politics of the Third Wave. Atlanta:Turner Publications.

Wright, S. 2006. "Design Matters: The Political Efficacy of Government-run Discussion Boards.” Pp.80-99 The Internet and Politics: Citizens, Voters, and Activists., edited by S. Oates, D. Owen, and K. Gibson. New York:Routledge.

Yankel, Elizabeth. 2006. "Archives and Manuscripts: Inviting the User Into the Virtual Archives" OCLC Systems and Services: International Digital Library Perspectives, Vol.22(3). 